\title{
Increased plasma sVCAM-1 is associated with severity in IgA nephropathy
}

\author{
Li Zhu, Sufang Shi, Lijun Liu, Jicheng Lv and Hong Zhang*
}

\begin{abstract}
Background: A considerable proportion of IgAN patients present with histological vasculitic/crescentic lesions in glomeruli, indicating activation of vascular inflammation. Using SVCAM-1, a well-proven marker for endothelial injury under inflammatory processes, we investigated vascular injury and its association with clinical and pathological manifestations in IgAN patients.

Methods: In this study, 327 biopsy-proven IgAN patients and 55 healthy controls were enrolled. The Oxford classification and two variables, Active Crescentic Lesion Percentage (ACLP) and Chronic Glomerular Lesion Percentage (CGLP), were used for evaluating pathological lesions. Human Umbilical Vein Endothelial Cells were treated with 25-400 ug/ml IgA1. sVCAM-1 in plasma and culture supernatant were measured by ELISA.

Results: Plasma sVCAM-1 in IgAN patients was significantly higher than healthy controls. In patients with IgAN, plasma sVCAM-1 was significantly correlated with eGFR, 24h urine protein excretion, tubular atrophy/interstitial fibrosis lesion and ACLP, but not CGLP. Meanwhile, compared to healthy volunteers, IgA1 from IgAN patients showed a tendency to increase the HUVECs supernatant SVCAM-1 expression. And IgA1 induced the sVCAM-1 increasing from HUVECs in time- and dose-dependent manner.

Conclusions: We found increased plasma SVCAM-1 in IgAN patients and its association with severe clinical and pathological manifestations, which might be partly resulted from effect of IgA1 to endothelial cells.
\end{abstract}

Keywords: sVCAM-1, IgA nephropathy, Vascular injury

\section{Background}

IgA nephropathy (IgAN) is the most common primary glomerulonephritis worldwide [1]. Except for the most characteristic finding, that is glomerular mesangial area deposition of IgA, a considerable proportion of IgAN patients present with histological vasculitic/crescentic lesions in glomeruli, accompanied by distinct neutrophils and/or monocytes infiltration, indicating the activation of vascular inflammation in IgAN [2]. Clinically, many patients with IgAN suffer hypertension at a relative young age, and some present with secondary malignant hypertension. In China, IgAN was reported as one of the major causes of secondary malignant hypertension, accounting for one-third of all secondary causes and

\footnotetext{
*Correspondence: hongzh@bjmu.edu.cn
Renal Division, Department of Medicine, Peking University First Hospital;

* Correspondence: hongzh@bjmu.edu.cn
Renal Division, Department of Medicine, Peking University First Hospital; Peking University Institute of Nephrology; Key Laboratory of Renal Disease, Ministry of Health of China; Key Laboratory of Chronic Kidney Disease Prevention and Treatment (Peking University), Ministry of Education, Beijing 100034, China
}

(c) 2013 Zhu et al.; licensee BioMed Central Ltd. This is an Open Access article distributed under the terms of the Creative Commons Attribution License (http://creativecommons.org/licenses/by/2.0), which permits unrestricted use, distribution, and reproduction in any medium, provided the original work is properly cited.
40\% of glomerular causes [3,4]. Although clinical and ment of vascular injury in IgAN, the pathogenesis of the vascular injury in IgAN is still unknown.

Vascular cell adhesion molecule 1 (VCAM-1) is endothelial ligand for integrins expressed on leukocytes and platelets, with the function of facilitation endothelial adhesion of circulating leukocytes. The endothelial expression of VCAM-1 is increased in response to inflammatory cytokines [5]. And the soluble ectodomain of VCAM-1 (sVCAM-1) is proteolytically released from the endothelial cell surface into the circulation upon endothelial activation and injury. Elevated plasma sVCAM-1 level was reported in many diseases, such as coronary and peripheral atherosclerosis, diabetes mellitus, systemic lupus erythematosus, Crohn's disease and so on [6-9]. Soluble vascular adhesion molecule-1 is now a well-proven marker for endothelial injury under inflammatory processes. 
In patients with chronic kidney disease (CKD), including IgAN, elevated plasma sVCAM-1 level was also observed and reported to be associated with impaired renal function [10-13]. But most studies were unable to state the major cause of high plasma levels of sVCAM-1, which could be either explained by increased production or decreased clearance. Recently, A.E.M. Stinghen et al. reported that exposure of endothelial cells to uremic plasma resulted in a time- and CKD-stage-dependent increased expression of sVCAM-1, suggesting a link between vascular activation, systemic inflammation and uremic toxicity [14]. IgA nephropathy, a study is needed to explore the cause of high plasma levels of sVCAM-1 and its association with vascular inflammation.

In the present study, we investigated the association of sVCAM-1 with clinical and pathological characteristics in patients with IgAN, and further detected the effect of IgA1 molecules on sVCAM-1 production by cultured endothelial cells in vitro to explore the mechanism of vascular inflammation in IgAN.

\section{Methods \\ Study population}

In the present study, a total of 382 subjects were enrolled, including 327 IgAN patients and 55 healthy volunteers with normal urine analysis and blood pressure. Diagnoses of IgAN were biopsy proven and confirmed by granular deposition of IgA in the glomerular mesangium by immunofluorescence detection, as well as by the deposition of electron dense material in mesangial ultra-structural examination. Patients with Henoch-Schonlein purpura, systemic lupus erythematosus, and chronic hepatic diseases were excluded by detailed clinical and laboratory examinations. In addition, 19 patients with minimal change disease (MCD), 30 with membranous nephropathy (MN) and 25 with lupus nephritis were recruited as control patients with other glomerular injury.

On the morning of renal biopsy and the inclusion in the study, plasma (EDTA) from patients and healthy volunteers was collected, divided into aliquots, and stored at $-80^{\circ} \mathrm{C}$ pending the measurement of sVCAM-1. Clinical manifestations at the time of renal biopsy, including serum IgA level, serum creatinine level, 24 hours urine protein excretion, history of hypertension and history of gross hematuria were collected from the clinical record. The glomerular filtration rate (GFR) of IgAN patients was calculated by the Modified Glomerular Filtration Rate Estimating Equation for Chinese [15]. Histologically, the Oxford classification was used for evaluating the pathological lesions [16]. Additionally, we used two indices to grossly distinguish the active and chronic glomerular lesion, which were Active Crescentic Lesion Percentage (ACLP) and Chronic Glomerular Lesion Percentage (CGLP). ACLP included the glomerular bearing cellular crescents, fibrocellular crescents and fibrinoid necrosis. CGLP included the glomerular having global sclerosis, segmental sclerosis and fibrous crescents.

The protocol for this study was approved by the Medical Ethics Committee of Peking University and informed written consent for this study was obtained from every participant.

\section{Detection of plasma sVCAM-1}

Plasma sVCAM-1 levels were determined using commercial ELISA kits according to the manufacturer's specifications (R\&D Systems, Minneapolis, MN, USA).

\section{Isolation of human plasma $\lg \mathrm{A} 1$}

Whole IgA1 was isolated by jacalin affinity chromatography from plasma as previous described [17]. In the present study, another small population, including 12 biopsy approved IgAN patients and 12 healthy controls, was used for IgA1 isolation. Plasma from the 24 individuals was introduced to jacalin affinity chromatography, one by one. Briefly, 3ml plasma from every subject were diluted 1:3 with $0.01 \mathrm{~mol} / \mathrm{l}$ phosphate buffered saline (PBS), filtered through a 0.22 um Corning syringe filter (Corning Glass Works, Corning, NY, USA) and then applied to a jacalin column, which was prepared with commercially available jacalin immobilized on cross-linked $4 \%$ beaded agarose (Pierce Chemical Company, Rockford, IL, USA) with an IgA1 binding capacity of more than $2 \mathrm{mg} / \mathrm{ml}$. The column was equilibrated with $0.01 \mathrm{~mol} / \mathrm{l} \mathrm{PBS}$ and IgA1 was eluted with $0.1 \mathrm{~mol} / \mathrm{l}$ melibiose (Sigma, St. Louis, MO, USA) in $0.01 \mathrm{~mol} / \mathrm{l}$ PBS. The eluted sample concentration and removal of melibiose were performed by pressure ultrafiltration using Vivaspin (Cat No: VS2021, Sartorius, Goettingen, Germany). The total protein concentrations of isolated IgA1 samples from the 24 individuals were tested using DC Protein Assay (Bio-Rad, Hercules, CA, USA). IgA1 was then aliquoted and stored at $-80^{\circ} \mathrm{C}$ pending cell culture experiments.

\section{Culture of endothelial cells with $\lg \mathrm{A} 1$}

Primary Human Umbilical Vein Endothelial Cells (HUVECs) and all the cell culture media, fetal bovine serum, supplements and extra cellular matrix were purchased from ScienCell ${ }^{\mathrm{TM}}$ Corporation (ScienCell $^{\mathrm{TM}}$, Carlsbad, CA, USA). Cells were cultured according to the manufacturer's specifications, in Endothelial Cell Medium (ECM) supplemented with Endothelial Cell Growth Supplement (EsCGS), 5\% fetal bovine serum, penicillin $\mathrm{G}(100 \mathrm{U} / \mathrm{ml})$ and streptomycin $(100 \mathrm{U} / \mathrm{ml})$ at $37^{\circ} \mathrm{C}$ in a humidified $5 \% \mathrm{CO}_{2}$ incubator. HUVECs were seeded into 24-well plates precoated with $1 \mathrm{ug} / \mathrm{cm}^{2}$ PolyL-Lysine (PLL) before experiment. After $12 \mathrm{~h}$ of serum starving, HUVECs were treated with $400 \mathrm{ug} / \mathrm{ml}$ whole IgA1 from 24 individuals, including $12 \mathrm{IgAN}$ patients and 12 healthy controls (we did not pool isolated IgA1 
from different IgAN patients and healthy controls together). For dose-dependent assay, 25-400 ug/ml whole IgA1 from one IgAN patient were used. For timedependent assay, HUVECs were treated with $200 \mathrm{ug} / \mathrm{ml}$ whole IgA1 from one IgAN patient for 6-48 hours.

\section{Detection of supernatant sVCAM-1}

Supernatant samples were separated from culture after $48 \mathrm{~h}$ of incubation (except for time-dependent assay, in which 6-48 $\mathrm{h}$ were used) and were stored at $-80^{\circ} \mathrm{C}$ until assay. Supernatant sVCAM-1levels were measured by ELISA as described above.

\section{Statistical analysis}

Descriptive statistical analyses were performed with SPSS10.0 software (SPSS Inc., USA). Continuous variables were compared by unpaired Student's t test or ANOVA (ANalysis Of VAriance between groups). Dichotomous and polychromous data were analyzed by the $\chi^{2}$ test. Correlations were performed by the Spearman rank test $(\rho)$. Results are expressed as means \pm SD. A p value of less than 0.05 was considered statistically significant.

\section{Results}

Clinical and pathological manifestations of patients with $\lg A N$

In our study, 327 IgAN patients were involved. The main clinical and pathological manifestations of them were summarized in Table 1 . Of them, 155 were males and 172 were females. The age at renal biopsy was $32.9 \pm 10.7$ year old. And $30.9 \%$ patients were with a history of macroscopic hematuria, $37.9 \%$ with a history of hypertension and $64.5 \%$ with moderate and severe proteinuria ( $>1 \mathrm{~g} / 24 \mathrm{~h}$ ). eGFR were $85.43 \pm 30.29 \mathrm{ml} / \mathrm{min}$.

\section{Plasma levels of sVCAM-1 in the IgAN patients}

The plasma levels of sVCAM-1 did not significantly differ between males and females in IgAN patients. Patients with IgAN presented higher plasma levels of sVCAM-1 than that in healthy controls $(726.66 \pm 290.35 \mathrm{ng} / \mathrm{ml} \mathrm{Vs}$ $520.23 \pm 137.51 \mathrm{ng} / \mathrm{ml}, \mathrm{p}<0.001)$. In patients with $\mathrm{MCD}$ and $\mathrm{MN}$, plasma levels of sVCAM-1 showed no difference to healthy controls (MCD: $485.09 \pm 203.37 \mathrm{ng} / \mathrm{ml}$, MN: $511.49 \pm 278.36 \mathrm{ng} / \mathrm{ml})$, while patients with LN presented higher levels of sVCAM-1 (LN: 958.53 \pm 601.49 , $\mathrm{p}$ value versus healthy controls $=0.001)$, which was similar to that found in IgAN patients.

\section{Correlations between plasma levels of sVCAM-1 and clinical characteristics of patients with IgAN}

In patients with IgAN, the plasma levels of sVCAM-1 were significantly correlated with eGFR $(\rho=-0.197, p<0.001)$, $24 \mathrm{~h}$ urinary protein excretion (UPE) $(\rho=0.198, p<0.001)$ and uric acid (UA) $(\rho=0.117, p=0.038)$ (Table 2), but not
Table 1 Clinical and pathological manifestations of enrolled IgAN patients

\begin{tabular}{|c|c|c|c|}
\hline \multicolumn{3}{|l|}{ Variables } & Manifestations \\
\hline \multicolumn{3}{|l|}{ Patients number } & 327 \\
\hline \multicolumn{3}{|l|}{ age $(y)$} & $32.9 \pm 10.7$ \\
\hline \multicolumn{3}{|l|}{ eGFR (ml/min) } & $85.43 \pm 30.29$ \\
\hline \multirow[t]{2}{*}{ gender } & \multicolumn{2}{|c|}{ Male } & 155 \\
\hline & \multicolumn{2}{|c|}{ Female } & 172 \\
\hline \multirow[t]{2}{*}{ macroscopic hematuria } & \multicolumn{2}{|c|}{ with } & 101 (30.9\%) \\
\hline & \multicolumn{2}{|c|}{ without } & $226(69.1 \%)$ \\
\hline \multirow[t]{2}{*}{ proteinuria } & \multicolumn{2}{|c|}{ more than $1 \mathrm{~g} / 24 \mathrm{~h}$} & $211(64.5 \%)$ \\
\hline & \multicolumn{2}{|c|}{ less than $1 \mathrm{~g} / 24 \mathrm{~h}$} & $116(35.5 \%)$ \\
\hline \multirow[t]{2}{*}{ hypertension } & \multicolumn{2}{|c|}{ with } & $124(37.9 \%)$ \\
\hline & \multicolumn{2}{|c|}{ without } & $203(62.1 \%)$ \\
\hline \multirow[t]{9}{*}{ Oxford classification } & \multirow[t]{2}{*}{ M } & MO & $123(37.6 \%)$ \\
\hline & & M1 & $204(62.4 \%)$ \\
\hline & \multirow[t]{2}{*}{$E$} & EO & 141 (43.1\%) \\
\hline & & E1 & $186(56.9 \%)$ \\
\hline & \multirow[t]{2}{*}{ S } & so & $68(20.8 \%)$ \\
\hline & & S1 & $259(79.2 \%)$ \\
\hline & \multirow[t]{3}{*}{$\mathrm{T}$} & T0 & $253(77.4 \%)$ \\
\hline & & $\mathrm{T} 1$ & 39 (11.9\%) \\
\hline & & $\mathrm{T} 2$ & $35(10.7 \%)$ \\
\hline
\end{tabular}

serum IgA levels, systolic blood pressure and diastolic blood pressure at the time of renal biopsy. Although the blood pressure at the time of renal biopsy did not correlated with plasma sVCAM-1 levels, IgAN patients with hypertension still had significantly elevated plasma sVCAM-1 levels than those without $(786.40 \pm 339.43 \mathrm{ng} / \mathrm{ml}$ Vs $690.17 \pm 249.75 \mathrm{ng} / \mathrm{ml}, \mathrm{p}<0.001$ ) (Figure 1a). Both group of patients, with or without hypertension, presented with higher plasma sVCAM-1 levels than healthy controls (without hypertension Vs healthy controls: $690.17 \pm 249.75 \mathrm{ng} / \mathrm{ml}$ Vs $520.23 \pm 137.51 \mathrm{ng} / \mathrm{ml}, \mathrm{p}<0.01$; with hypertension Vs healthy controls: $786.40 \pm 339.43 \mathrm{ng} / \mathrm{ml}$ Vs $520.23 \pm 137.51$ $\mathrm{ng} / \mathrm{ml}, \mathrm{p}<0.01$ ) (Figure 1a). The plasma levels of sVCAM-1 showed no difference between IgAN patients with or without gross hematuria history (Figure 1b).

Table 2 Correlations between plasma levels of sVCAM-1 and clinical and histological manifestations of patients with IgAN

\begin{tabular}{lllllllll}
\hline & eGFR & UPE & IgA & UA & SBP & DBP & ACLP & CGLP \\
\hline$\rho^{*}$ & -0.197 & 0.198 & 0.062 & 0.117 & 0.077 & 0.053 & 0.182 & 0.054 \\
p value & $<0.001$ & $<0.001$ & 0.293 & 0.038 & 0.168 & 0.344 & 0.001 & 0.327
\end{tabular}

* Pearson's correlation coefficient. 


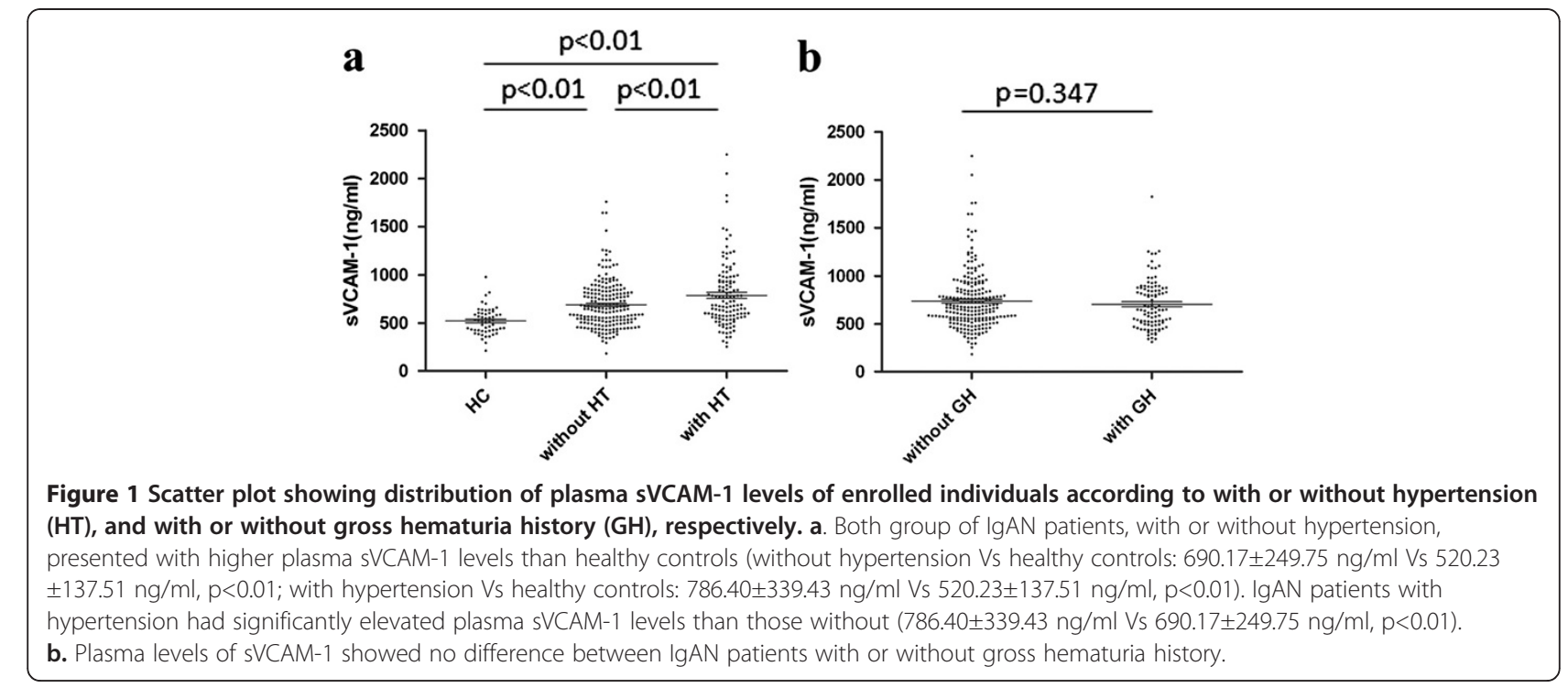

Correlations between plasma levels of sVCAM-1 and pathological characteristics of patients with IgAN

Patients with higher scores in the variable tubular atrophy/ interstitial fibrosis showed significantly higher sVCAM-1 (T2:T1:T0=941.97 $\pm 339.95 \mathrm{ng} / \mathrm{ml}: 699.27 \pm 213.43 \mathrm{ng} / \mathrm{ml}: 701$. $10 \pm 281.76 \mathrm{ng} / \mathrm{ml}, \mathrm{p}<0.001$ ), patients with higher scores in the variables mesangial hypercellularity showed relative higher sVCAM-1, although do not reach the statistic significance (M1:M0=749.88 $\pm 279.76 \mathrm{ng} / \mathrm{ml}: 688.14 \pm 304.38 \mathrm{ng} / \mathrm{ml}$, $\mathrm{p}=0.062$ ) (Table 3). Furthermore, the plasma levels of sVCAM-1 significantly correlated with Active Crescentic Lesion Percentage (ACLP), but not Chronic Glomerular Lesion Percentage (CGLP) (Table 2).

sVCAM-1 expression induced by IgA 1 in HUVECs

At first, using HUVEC as a model of endothelial cells, we tested the SVCAM-1 induction effect by IgA1 from 24 different subjects, which were 12 IgAN patients and 12 healthy volunteers. Compared to IgA1 from healthy

Table 3 Plasma sVCAM-1 levels of IgAN patients with different histological lesions, according to Oxford classification

\begin{tabular}{lcccc}
\hline Oxford classification & Number & sVCAM-1 (ng/ml) & p value \\
\hline M & 0 & 123 & $688.14 \pm 304.38$ & 0.062 \\
& 1 & 204 & $749.88 \pm 279.76$ & \\
E & 0 & 141 & $716.72 \pm 276.41$ & 0.591 \\
& 1 & 186 & $734.20 \pm 301.01$ & \\
$\mathrm{~S}$ & 0 & 68 & $755.98 \pm 389.63$ & 0.46 \\
& 1 & 259 & $718.96 \pm 258.49$ & \\
$\mathrm{~T}$ & 0 & 253 & $701.10 \pm 281.76$ & $<0.001$ \\
& 1 & 39 & $699.27 \pm 213.43$ & \\
& 2 & 35 & $941.97 \pm 339.95$ & \\
\hline
\end{tabular}

volunteers, IgA1 form IgAN patients showed a tendency to increase the HUVECs supernatant SVCAM-1 expression, although did not reach the statistic significance (Figure 2). Next, we detected the effect of IgA1 on the sVCAM-1 expression in vitro. We found that IgA1 increased the sVCAM-1 expression in HUVECs culture supernatant in a time- and dose-dependent manner. The sVCAM-1 level in HUVECs supernatant significantly elevated upon $48 \mathrm{~h}$ treatment with 200-400 ug/ml IgA1 (Figure 3a). And significantly increased supernatant sVCAM-1 level could be detected at $48 \mathrm{~h}$ (Figure 3b).

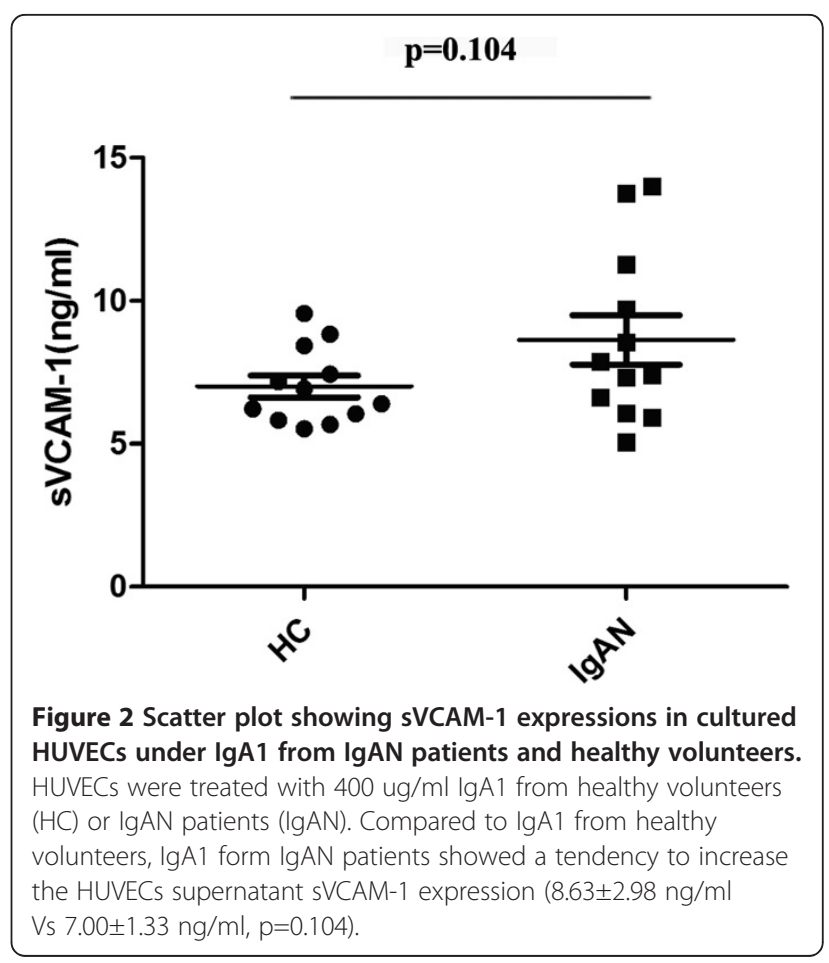




\section{Discussion}

Patients with IgA nephropathy presented with variable clinical findings, histological impairments and long-term renal outcomes [18]. In the present study, we enrolled 327 patients with IgAN. Among them, 37.9\% patients presented with clinical hypertension at the time of renal biopsy, which was well-approved to be an independent risk factor for long-term renal outcome [19,20]; and $56.9 \%$ patients presented with histological endocapillary hypercellularity, according to Oxford classification. This supported previous observations that a great mass of IgAN patients suffered vascular injury [21]. When we used sVCAM-1 as the marker for vascular injury, especially inflammation injury, results showed that patients with IgAN had significantly elevated plasma sVCAM-1 compared to healthy controls, which was in accordance with previous reports in other IgAN patients' cohorts [11]. Similarly, in patients with lupus nephritis, in which condition vascular injury were commonly reported, sVCAM-1 levels were also significantly higher. But in some other glomerular injury conditions, such as MCD and $\mathrm{MN}$, patients showed comparable sVCAM-1 levels to healthy controls. Therefore, we regarded sVCAM-1 as an indicator to vascular injury other than glomerular injury.

Hypertension is a well accepted clinical finding for vascular injury, but still over $70 \%$ patients in our present study did not have this obvious symptom for vascular injury. Although without hypertension, they also showed significantly higher plasma sVCAM-1 compared to healthy controls, while the patients with hypertension presented with even higher plasma sVCAM-1. From above findings, we suggested that plasma sVCAM-1 as another marker for vascular injury, except for clinical hypertension, and IgAN patients suffered vascular injury are likely underestimated.
In addition, we described the significant association between plasma sVCAM-1 level and clinical findings, including eGFR and urinary protein excretion. D'Amico G has already came to the concordance that impairment of renal function, severe proteinuria, and arterial hypertension were the strongest and more reliable clinical predictors of an unfavorable outcome after critical analysis of results of 30 studies [22]. Since plasma sVCAM-1 level in patients with IgAN associated with all the three risk factors, we speculated the patients had higher plasma sVCAM-1 levels would be in more severe clinical states of IgAN.

Accordingly, we found the significantly different plasma sVCAM-1 level among patients with different tubular atrophy/interstitial fibrosis lesion judged by Oxford classification, an independent predictor of long-term renal outcome measured by multivariate analysis. This result indicated that plasma sVCAM-1 level in patients was a marker not only for severe clinical state but also for severe histological lesion of IgAN.

Oxford classification was derived from a group of IgAN patients without most acute and rapidly progressive disease courses and more than $50 \%$ of them without crescent, but many of our IgAN patients in the present study had crescentic lesion in the glomeruli. Therefore, we used two variables, Active Crescentic Lesion Percentage (ACLP) and Chronic Glomerular Lesion Percentage (CGLP), to roughly distinguish the acute and chronic histological lesions. We surprisingly found that only ACLP was significantly associated with plasma sVCAM-1 level, not CGLP. It is important for us to point out that plasma sVCAM-1 level was a marker for acute crescentic lesion in patients with IgAN. Crescentic lesion is actually a kind of glomerular vascular inflammation, so we considered elevated plasma sVCAM-1 level in patients with IgAN can at least partly ascribed to glomerular vascular inflammation lesion.
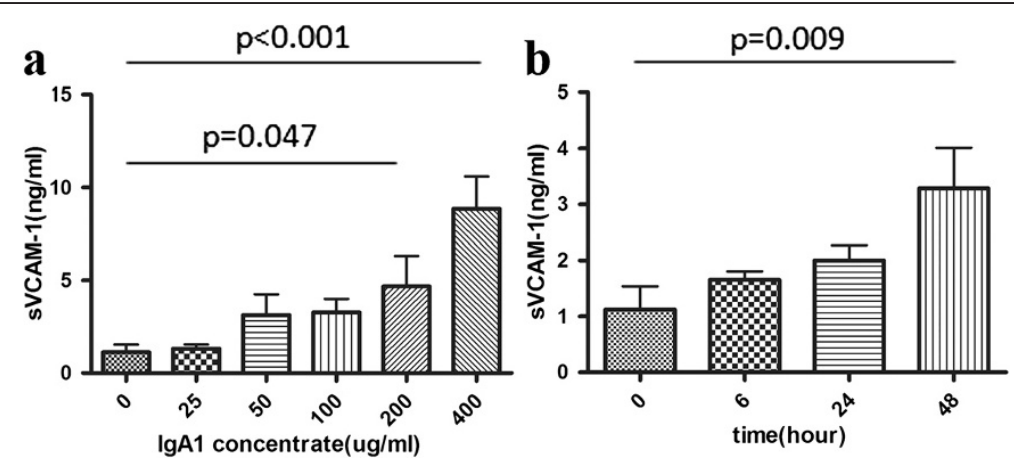

Figure 3 sVCAM-1 expressions in cultured HUVECs under different doses of IgA1 treatment for different time durations. a. HUVECs were treated with $25-400 \mathrm{ug} / \mathrm{ml}$ IgA1 for 48 hours. IgA1 induced the sVCAM-1 expression in cultured HUVECs supernatant in a dose-dependent manner. Significantly increased supernatant sVCAM-1 level could be detected at $200 \mathrm{ug} / \mathrm{ml}$ and $400 \mathrm{ug} / \mathrm{ml}$ lgA1 ( $p=0.047$ for $200 \mathrm{ug} / \mathrm{ml}, \mathrm{p}<0.001$ for $400 \mathrm{ug} / \mathrm{ml}$ ). b. HUVECS were treated with $200 \mathrm{ug} / \mathrm{ml}$ IgA1 for 6-48 hours. IgA1 induced the sVCAM-1 expression in cultured HUVECs supernatant in a time-dependent manner. The sVCAM-1 level in HUVECs supernatant significantly elevated upon $48 \mathrm{~h}$ treatment ( $\mathrm{p}=0.009)$. 
Furthermore, we wanted to explore the reason of the elevated sVCAM-1 in IgAN. In recent years, lots of efforts have been made to uncover the pathogenesis of IgAN, and some significant progress has been achieved in this field [23-25]. Increasing evidences indicated abnormal IgA1 molecules from IgAN patients to be the initial factor to induce glomerular mesangial cells proliferation and secondary podocytes and tubular epithelial cells injury [26-29]. Regarding to endothelial cells, less evidence was available. We hypothesized that abnormal IgA1 molecules from IgAN patients had unique activity to promote sVCAM-1 expression from endothelial cells. In order to exclude other reasons induced sVCAM-1 elevation in IgAN patients, such as inflammation induced increased production by inflammatory cells and eGFR induced decreased clearance, an in vitro cell model was used. In the present study, we inferred that IgA1 molecules from IgAN patients could promote sVCAM-1 expression of endothelial cells for the following three evidences: (1) the same amount of IgA1 from IgAN patients showed a tendency to increase endothelial sVCAM-1 expression; (2) patients with IgAN presented with higher levels of IgA1 compared to healthy controls; (3) IgA1 induced the sVCAM-1 increasing from HUVECs in dose-dependent manner. However, it was very possible that many other factors, like inflammatory cells activation and decreased clearance due to impaired renal function were also contributed to elevated sVCAM-1 in IgAN patients, which we could not determine from present study.

\section{Conclusions}

In the present study, we used sVCAM-1 as a marker to investigate vascular injury and its association with clinical and pathological characteristics in patients with IgAN. We found that the plasma levels of sVCAM-1 in patients with IgAN were increased. And increased plasma sVCAM-1 was associated with severe clinical and pathological findings, especially acute glomerular vascular inflammation lesion in patients with IgAN, which might be partly resulted from the effect of IgA1 to endothelial cells.

\footnotetext{
Abbreviations

IgAN: IgA nephropathy; sVCAM-1: Soluble Vascular cell adhesion molecule 1; CKD: Chronic kidney disease; eGFR: Estimated glomerular filtration rate; ACLP: Active Crescentic Lesion Percentage; CGLP: Chronic Glomerular Lesion
} Percentage; HUVECs: Human Umbilical Vein Endothelial Cells.

\section{Competing interests}

The authors have declared that no competing interests exist.

\section{Authors' contributions}

LZ participated in the design of the study, carried out the molecular biological and cell biological studies and drafted the manuscript. SS carried out the pathological classification. LL recruited patients and participated in the ELISA detection. JL recruited patients and performed the statistical analysis. $\mathrm{HZ}$ conceived of the study, and participated in its design and coordination and helped to draft the manuscript. All authors read and approved the final manuscript.

\section{Acknowledgements}

This work was supported by the National Science Foundation for Youths of China (Grant No. 81000297), Peking University Clinical Research Program (PUCRP201102) and the National Natural Science Foundation for Innovative Research Groups of China (Grant No. 81021004).

Received: 3 May 2012 Accepted: 15 January 2013

Published: 22 January 2013

\section{References}

1. D'Amico G: The commonest glomerulonephritis in the world: IgA nephropathy. Q J Med 1987, 64:709-727.

2. Barratt J, Feehally J: IgA nephropathy. J Am Soc Nephrol 2005, 16:2088-2097.

3. Chen Y, Tang Z, Yang G, Shen S, Yu Y, Zeng C, Chen H, Liu ZH, Li LS: Malignant hypertension in patients with idiopathic IgA nephropathy. Kidney Blood Press Res 2005, 28:251-258.

4. Zhou F, Liu Y, Zou W, Zhang Y, Wang H: Malignant hypertension presenting with renal damage: a clinical and pathological analyses. Zhonghua Nei Ke Za Zhi 2001, 40:165-168.

5. Constans J, Conri C: Circulating markers of endothelial function in cardiovascular disease. Clin Chim Acta 2006, 368:33-47.

6. Glowinska B, Urban M, Peczynska J, Florys B: Soluble adhesion molecules (sICAM-1, sVCAM-1) and selectins (sE-selectin, sP-selectin, sL-selectin) levels in children and adolescents with obesity, hypertension, and diabetes. Metabolism 2005, 54:1020-1026.

7. Baraczka K, Pozsonyi T, Szongoth M, Nékám K, Megyeri A, Balogh Z, Jakab L: A study of increased levels of soluble vascular cell adhesion molecule-1 (sVCAM-1) in the cerebrospinal fluid of patients with multiple sclerosis and systemic lupus erythematosus. Acta Neurol Scand 1999, 99:95-99.

8. Goke M, Hoffmann JC, Evers J, Krüger H, Manns MP: Elevated serum concentrations of soluble selectin and immunoglobulin type adhesion molecules in patients with inflammatory bowel disease. $J$ Gastroenterol 1997, 32:480-486.

9. Li YH, Teng JK, Tsai WC, Tsai LM, Lin LJ, Chen JH: Elevation of soluble adhesion molecules is associated with the severity of myocardial damage in acute myocardial infarction. Am J Cardiol 1997, 80:1218-1221.

10. Suliman ME, Qureshi AR, Heimburger O, Lindholm B, Stenvinkel P: Soluble adhesion molecules in end-stage renal disease: a predictor of outcome. Nephrol Dial Transplant 2006, 21:1603-1610.

11. Nelson CL, Karschimkus CS, Dragicevic G, Packham DK, Wilson AM, O'Neal D, Becker GJ, Best JD, Jenkins AJ: Systemic and vascular inflammation is elevated in early IgA and type 1 diabetic nephropathies and relates to vascular disease risk factors and renal function. Nephrol Dial Transplant 2005, 20:2420-2426.

12. Stenvinkel $P$, Lindholm $B$, Heimburger $M$, Heimbürger $O$ : Elevated serum levels of soluble adhesion molecules predict death in pre-dialysis patients: association with malnutrition, inflammation, and cardiovascular disease. Nephrol Dial Transplant 2000, 15:1624-1630.

13. Mrowka C, Heintz B, Sieberth HG: VCAM-1, ICAM-1, and E-selectin in IgA nephropathy and Schonlein-Henoch syndrome: differences between tissue expression and serum concentration. Nephron 1999, 81:256-263.

14. Stinghen AE, Goncalves SM, Martines EG, Nakao LS, Riella MC, Aita CA, Pecoits-Filho R: Increased plasma and endothelial cell expression of chemokines and adhesion molecules in chronic kidney disease. Nephron Clin Pract 2009, 111:c117-c126.

15. Ma YC, Zuo L, Chen JH, Luo Q, Yu XQ, Li Y, Xu JS, Huang SM, Wang LN, Huang $W$, Wang $M, X u G B$, Wang $H Y$ : Modified glomerular filtration rate estimating equation for Chinese patients with chronic kidney disease. J Am Soc Nephrol 2006, 17:2937-2944.

16. Working Group of the International IgA Nephropathy Network and the Renal Pathology Society, Roberts IS, Cook HT, Troyanov S, Alpers CE, Amore A, Barratt J, Berthoux F, Bonsib S, Bruijn JA, Cattran DC, Coppo R, D'Agati V, D'Amico G, Emancipator S, Emma F, Feehally J, Ferrario F, Fervenza FC, Florquin S, Fogo A, Geddes CC, Groene HJ, Haas M, Herzenberg AM, Hill PA, Hogg RJ, Hsu SI, Jennette JC, Joh K, Julian BA, Kawamura T, Lai FM, Li LS, Li PK, Liu ZH, Mackinnon B, Mezzano S, Schena FP, Tomino Y, Walker PD, Wang H, Weening JJ, Yoshikawa N, Zhang H: The Oxford classification of 
IgA nephropathy: pathology definitions, correlations, and reproducibility. Kidney Int 2009, 76:546-556.

17. Gao YH, Xu LX, Zhang JJ, Zhang Y, Zhao MH, Wang HY: Differential binding characteristics of native monomeric and polymeric immunoglobulin A1 (IgA1) on human mesangial cells and the influence of in vitro deglycosylation of IgA1 molecules. Clin Exp Immunol 2007, 148:507-514.

18. D'Amico G, Colasanti G, Barbiano di Belgioioso G, Fellin G, Ragni A, Egidi F, Radaelli L, Fogazzi G, Ponticelli C, Minetti L: Long-term follow-up of IgA mesangial nephropathy: clinico-histological study in 374 patients. Semin Nephrol 1987, 7:355-358

19. D'Amico G: Natural history of idiopathic IgA nephropathy and factors predictive of disease outcome. Semin Nephrol 2004, 24:179-196.

20. Johnston PA, Brown JS, Braumholtz DA, Davison AM: Clinico-pathological correlations and long-term follow-up of 253 United Kingdom patients with IgA nephropathy. A report from the MRC Glomerulonephritis Registry. Q J Med 1992, 84:619-627.

21. Lv J, Zhang H, Zhou Y, Li G, Zou W, Wang H: Natural history of immunoglobulin A nephropathy and predictive factors of prognosis: a long-term follow up of 204 cases in China. Nephrology (Carlton) 2008, 13:242-246.

22. D'Amico G: Natural history of idiopathic IgA nephropathy: role of clinical and histological prognostic factors. Am J Kidney Dis 2000, 36:227-237.

23. Suzuki H, Fan R, Zhang Z, Brown R, Hall S, Julian BA, Chatham WW, Suzuki Y, Wyatt RJ, Moldoveanu Z, Lee JY, Robinson J, Tomana M, Tomino Y, Mestecky J, Novak J: Aberrantly glycosylated IgA1 in IgA nephropathy patients is recognized by $\lg G$ antibodies with restricted heterogeneity. J Clin Invest 2009, 119:1668-1677.

24. Suzuki H, Moldoveanu Z, Hall S, Brown R, Vu HL, Novak L, Julian BA, Tomana M, Wyatt RJ, Edberg JC, Alarcón GS, Kimberly RP, Tomino Y, Mestecky J, Novak J: IgA1-secreting cell lines from patients with IgA nephropathy produce aberrantly glycosylated IgA1. J Clin Invest 2008, 118:629-639.

25. Gharavi AG, Yan Y, Scolari F, Schena FP, Frasca GM, Ghiggeri GM, Cooper K Amoroso A, Viola BF, Battini G, Caridi G, Canova C, Farhi A, Subramanian V, Nelson-Williams C, Woodford S, Julian BA, Wyatt RJ, Lifton RP: IgA nephropathy, the most common cause of glomerulonephritis, is linked to 6q22-23. Nat Genet 2000, 26:354-357.

26. Coppo R, Fonsato V, Balegno S, Ricotti E, Loiacono E, Camilla R, Peruzzi L, Amore A, Bussolati B, Camussi G: Aberrantly glycosylated lgA1 induces mesangial cells to produce platelet-activating factor that mediates nephrin loss in cultured podocytes. Kidney Int 2010, 77:417-427.

27. Lai KN, Leung JC, Chan LY, Saleem MA, Mathieson PW, Tam KY, Xiao J, Lai FM, Tang SC: Podocyte injury induced by mesangial-derived cytokines in IgA nephropathy. Nephrol Dial Transplant 2009, 24:62-72.

28. Lai KN, Leung JC, Chan LY, Saleem MA, Mathieson PW, Lai FM, Tang SC: Activation of podocytes by mesangial-derived TNF-a: glomerulopodocytic communication in IgA nephropathy. Am J Physiol Renal Physiol 2008, 294:F945-F955.

29. Chan LY, Leung JC, Tsang AW, Tang SC, Lai KN: Activation of tubular epithelial cells by mesangial-derived TNF-a: glomerulotubular communication in IgA nephropathy. Kidney Int 2005, 67:602-612.

doi:10.1186/1471-2369-14-21

Cite this article as: Zhu et al:: Increased plasma SVCAM-1 is associated with severity in IgA nephropathy. BMC Nephrology 2013 14:21.

\section{Submit your next manuscript to BioMed Central and take full advantage of:}

- Convenient online submission

- Thorough peer review

- No space constraints or color figure charges

- Immediate publication on acceptance

- Inclusion in PubMed, CAS, Scopus and Google Scholar

- Research which is freely available for redistribution

Submit your manuscript at www.biomedcentral.com/submit 